\title{
Sebaran Parameter Klorofil-a di Perairan Pulau Ternate Hubungnya dengan Hasil Tangakapn Ikan Pelagis Kecil
}

\section{(Distribution of Chlorophyll-a Parameters in Ternate Island Waters in Relation to Small Pelagic Fish Results)}

\author{
Armain Naim ${ }^{1 凶}$ dan Muzakir Hi. Sultan ${ }^{1}$ \\ ${ }^{1}$ Universitas Muhmmadiyah Maluku Utara, Jl. KH. A. Dahlan NO. 100, Kel. Sasa, Kec. Ternate Selatan, Ternate Indonesia, Email : \\ armainnaim@gmail.com, muzakirhis@yahoo.co.ic
}

\author{
■ Info Artikel: \\ Diterima : 14 Ags 2019 \\ Disetujui : 03 Sept. 2019 \\ Dipublikasi : 5 Des. 2019

\section{瞜 Artikel Penelitian} \\ Keyword: \\ Klorofil-a, Pelagis, \\ Oseanografi, Catch.
}

X Korespondensi:
Armain Naim
Universitas
Muhammadiyah Maluku
Utara
Ternate, Indonesia
Email: armainnaim@gmail.com

\section{(c) (1)(2)}

Copyright@ Oktober 2019

AGRIKAN

\begin{abstract}
Abstrak. Penelitian ini dilaksanakan selama bulan Mei sampai Juli 2019 bertempat di perairan pulau Ternate, dengan tujuan untuk mengkaji sebaran konsentrasi klorofil-a dan hubungannya dengan hasil tangkapan ikan pelagis kecil di perairan Pulau Ternate. Pengguanaan metode eksperimtal fishing, dengan data hasil penelitian di analisis menggunakan analisis SIG dan analisis statistik. Hasil penelitian di dapat bahwa konsentrasi klorofil-a memberikan respon terhadap kehadiran ikan pelagis kecil di daerah Perairan Pulau Ternate dengan nilai rata-rata selama penelitian berkisar antara $0.21-0.26 \mathrm{mg} / \mathrm{m3}$, dimana konsentrasi klorofil-a memiliki hubungan yang nyata dengan koefisien korelasi sebesar 0.84 .
\end{abstract}

\begin{abstract}
This research was conducted from May to July 2019 in the waters of Ternate Island, with the aim to examine the distribution of chlorophyll-a concentrations and their relationship with the catch of small pelagic fish in Ternate Island waters. The use of experimental fishing methods, with research data analyzed using GIS analysis and statistical analysis. The results of the study found that the concentration of chlorophyll-a responded to the presence of small pelagic fish in the waters of Ternate Island with an average value during the study ranging from 0.21 $0.26 \mathrm{mg} / \mathrm{m} 3$, where the concentration of chlorophyll-a had a significant relationship with the correlation coefficient of 0.84 .
\end{abstract}

\section{PENDAHULUAN}

Wilayah pesisir pantai dan laut Pulau Ternate merupakan wilayah yang potensial untuk kegiatan perekonomian dan dikembangkan kegiatan usaha perikanan. Usaha penangkapan ikan pelagis adalah salah satu kegiatan usaha penangkapan yang memiliki nilai komersial cukup tinggi khususnya pemanfaatan untuk produksi dan konsumsi (Tangke et al, 2018ab)

Untuk mengoptimalkan pesisir pantai dan laut sebagai wilayah kegiatan penangkapan dan sumber pendapatan, maka sangat diperlukan memerlukan dukungan ilmu pengetahuan dan teknologi dalam mengoptimalkan pemanfaatan sumberdaya perikanan pelagis terutama kajian parameter oseanografi.

Pola penyebaran ikan bisa dilihat dengan mengetahui parameter oseanografi seperti suhu permukaan laut dan klorofil-a di perairan (Tangke et al., 2015). Nilai konsentrasi klorofil biasanya dijadikan sebagai indikator produktivitas perairan atau tingkat kesuburan perairan dan juga menjadi daya tarik bagi ikan pelagis yang bersifat plankton feeder (Hadikusumah, 2008). Konsentrasi klorofila adalah salah satu parameter oseanografi yang 
paling sering di kaji untuk penentuan daerah penangkapan ikan (Tangke et al, 2014).

Penelitian ini laksanakan untuk mengkaji sebaran konsentrasi klorofil-a dan hubungannya dengan hasil tangkapan ikan pelagis kecil di perairan Pulau Ternate.

\section{BAHAN DAN METODE}

Penelitian ini dilaksanakan selama bulan Mei sampai Juli 2019 bertempat di perairan pulau Ternate, dengan metode eksperimtal fishing, dengan data penelitian berupa data hasil tangkapan, posisi tangkap dan nilai konsentrasi klorofil-a yang di ekstrak dari citra satelit Aqua MODIS level 2. Data hasil penelitian kemudian di analisis dengan menggunakan analisis SIG dan analisis statistik.

\section{HASIL DAN PEMBAHASAN \\ 3.1. Hasil}

Hasil penelitian didapat bahwa jenis hasil tangkapan adalah ikan tongkol, ikan layang dan ikan selar dengan produksi selama penelitian bulan Mei-Juli 2019 masing-masing adalah 1.583 $\mathrm{kg}, \quad 2.114 \mathrm{~kg} 2.410 \mathrm{~kg}$ (Gambar 1). Sebaran konsentrasi klorofil-a selama bulan Mei - Juli 2019 pada daerah perairan Pulau Ternate berdasarkan hasil analisis SIG dapat di lihat pada Gambar 2.

Hubungan konsentrasi klorofil-a dengan hasil tangkapan dapat dilihat pada Gambar 3 dan Gambar 4.

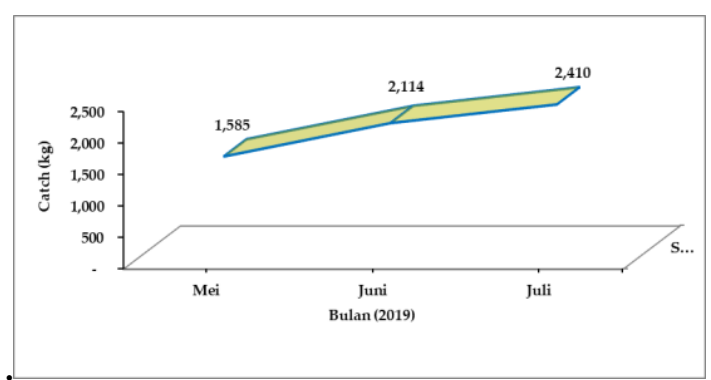

Gambar 1. Produksi Ikan Pelagis Kecil selama Penelitian
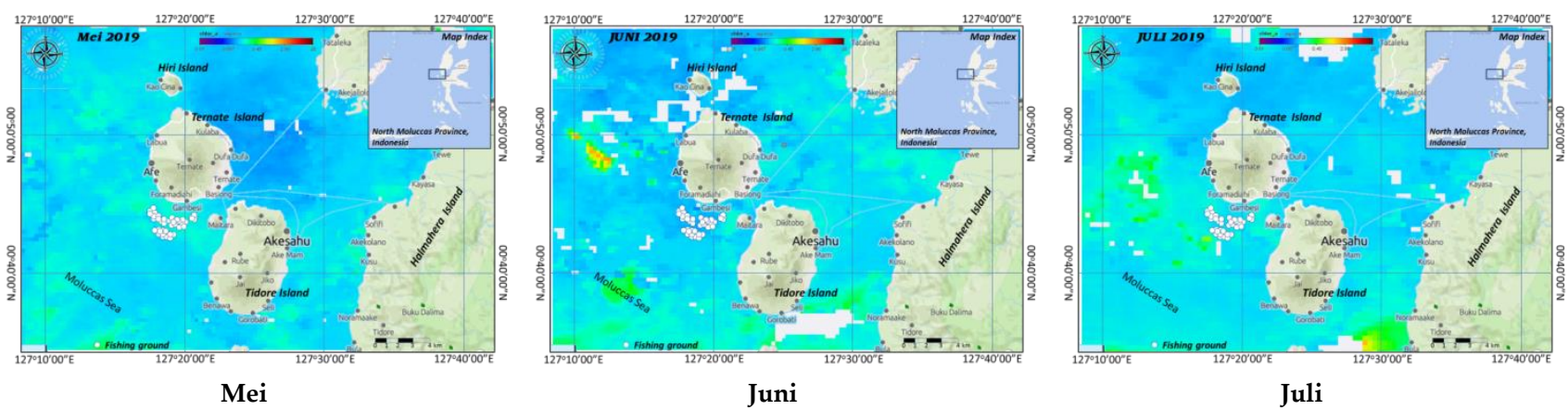

Gambar 2. Sebaran Konsentrasi Klorofil-a di Perairan Pulau Ternate selama Bulan Mei-Juni 2019

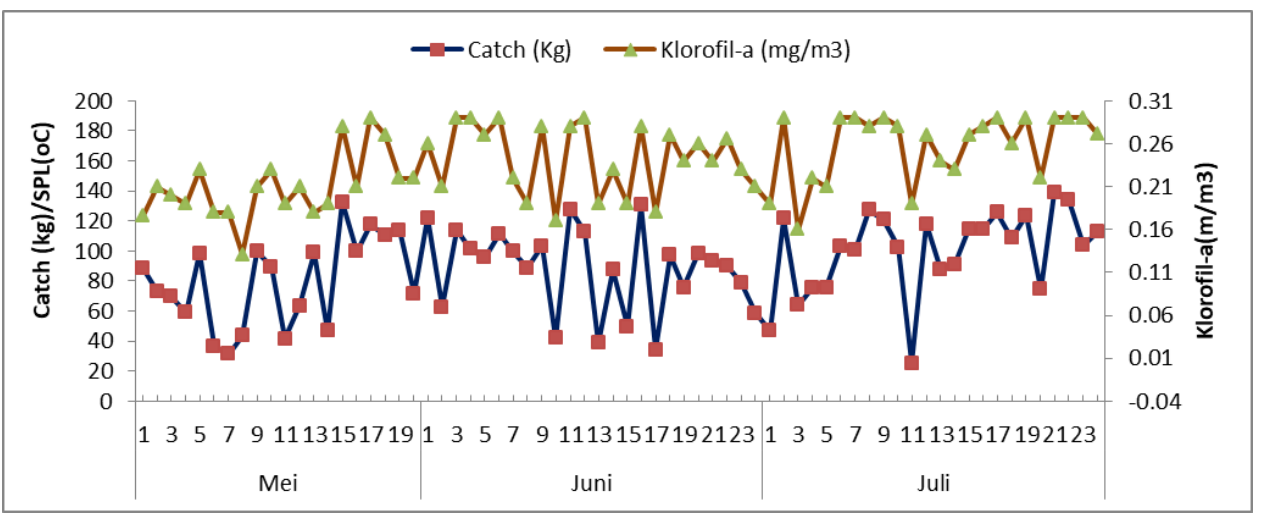

Gambar 3. Sebaran Konsentrasi Klorofil-a di Perairan Pulau Ternate selama Bulan Mei-Juni 2019 


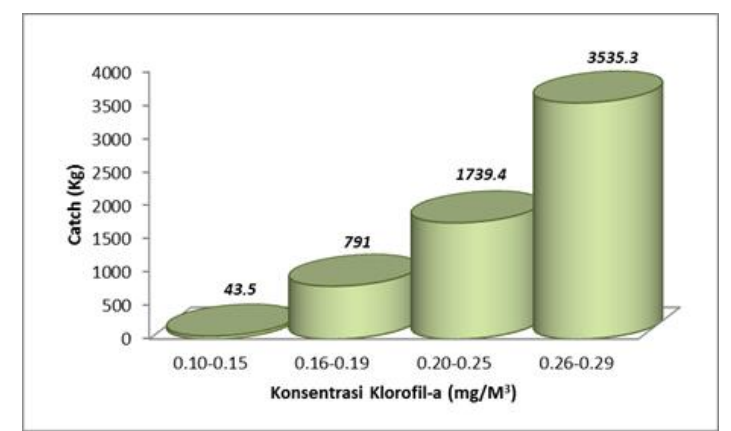

Gambar 4. Sebaran Konsentrasi Klorofil-a di Perairan Pulau Ternate selama Bulan Mei-Juni 2019

\subsection{Pembahasan}

Gambar 1, terlihat bahwa produksi ikan pelagis kecil mengalami peningkatan dari bulan Mei-Junli 2019 dengan kondisi hasil tangkapn yang selalu mengalami dari $1.585 \mathrm{~kg}$ naik ke 2.114 dan menjadi $2.410 \mathrm{~kg}$ pada bulan Juli 2019 . Kenaikan jumlah hasil tangkapan selama penelitian di duga terjadi karena kondisi trip penangkapan akibat kondisi perairan, dimana pada bulan Mei kondisi perairan yang berada di musim peralihan I dan masih banyak di pengaruhi oleh musim barat yang menyebabkan kondisi perairan bergelombang sehingga nelayan jarang melaut.

Nilai konsentrasi klorofil-a di Peraian Pulau Ternate pada bulan Mei - Juli 2019 dapat dilihat pada Table 1.

Tabel 1. Nilai Konsentrasi Klorofil-a di Perairan Pulau Maitara selama Bulan Mei-Juli 2019

\begin{tabular}{cccc}
\hline \multirow{2}{*}{ Bulan } & \multicolumn{3}{c}{ Nilai Konsentrasi Klorofil-a $\left(\mathrm{mg} / \mathrm{m}^{3}\right)$} \\
\cline { 2 - 4 } & Min & Maks & Rata-rata \\
\hline Mei & 0.131 & 0.29 & 0.21 \\
Juni & 0.17 & 0.29 & 0.24 \\
Juli & 0.16 & 0.29 & 0.26 \\
\hline
\end{tabular}

Klorofil-a merupakan salah satu komponen biologi laut yang penting terutama untuk memetakan potensi sumberdaya ikan. Hasil Analisis SIG (Gambar 2), terlihat bahwa rata-rata nilai konsentrasi klorofil-a selama bulan Mei sampai Juli 2019 seperti terlihat pada Table 1, kondisi nilai rata-rata ini lebih tinggi dari dari 0.2 $\mathrm{mg} / \mathrm{m}^{3}$. Menurut Nontji (2002), bahwa nilai ratarata klorofil-a diperairan Indonesia berada pada kisaran di atas $0,2 \mathrm{mg} / \mathrm{m}^{3}$, dimana ini nilai ini mengindikasikan daerah Perairan Pulau Ternate dapat dijadikan sebagai daerah penangkapan yang baik, menurut Gower (1972) dalam Tangke et al (2015), bahwa konsentrasi klorofil-a diatas 0.2 $\mathrm{mg} / \mathrm{m}^{3}$ dapat mengindikasikan keberadaan plankton yang cukup untuk menjaga kelangsungan hidup ikan. Amri K (2008), terdapat korelasi yang kuat antara peningkatan kosentrasi kesuburan perairan (klorofil-a tinggi 1,0 sampai dengan 1,5 mg m-3) akibat terjadi upwelling.

Hasil analisis statistic didapat bahwa konsentrasi klorofil-a yang memiliki hubungan yang nyata dengan hasil tangkapan ikan pelagis kecil dengan nilai koefisien korelasi 0,84 atau $84 \%$ sebaran ikan pelagis kecil di pengaruhi oleh konsentrasi klorofil-a, sedangkan $16 \%$ di pengaruhi oleh faktor lain. Pada Gambar 4. Terlihat bahwa kenaikan nilai konsentrasi klorofila- dibarengi dengan kenaikan nilai hasil tangkapan ikan pelagis kecil.

\section{PENUTUP}

Konsentrasi klorofil-a ini cukup untuk memberikan respon terhadap kehadiran ikan pelagis kecil di daerah Perairan Pulau Ternate dengan nilai rata-rata selama penelitian berkisar antara $0.21-0.26 \mathrm{mg} / \mathrm{m}^{3}$, dimana konsentrasi klorofil-a memiliki hubungan yang nyata dengan koefisien korelasi sebesar 0.84 .

\section{UCAPAN TERIMA KASIH.}

Penulis mengucapkan terima kasih kepada DRPM Direktorat Kemenristek Dikti yang telah memberikan dana penelitian melalui hibah Penelitian Dosen Pemula (PDP). 


\section{REFERENSI}

DKP Provinsi Maluku Utara, 2015. Laporan Tahunan Potensi Perikanan Laut di Maluku Utara

Hadikusumah. 2008. Karakteristik Parameter Fisika dan Kandungan Klorofil-a di Laut Jawa. Jurnal Ilmu Kelautan.

Hasyim, B., 1993. Prospek Pemanfaatan Teknologi Penginderaan Jauh Untuk Inventarisasi Sumberdaya Laut dan Perairan Pantai. Bidang Matra Laut LAPAN. Jakarta.

Hela, I., dan T. Laevastu. 1970. Fisheries Oceanography. Fishing News (Books) LTD. London.

Laevastu, T., And Hayes, M.L. 1981. Fiheries Oseanography and Echology. Fishing News

Book. London.

Nontji A., 2002. Laut Nusantara. Djambatan. Jakarta.

Nybaken, J. W. 1982. Biologi Laut : Suatu Pendekatan Ekologis. PT. Gramedia. Jakarta.

Tubalawony, Simon. (2007). Klorofil-a dan Nutrien serta Interelasinya dengan Dinamika Massa Air di Perairan Barat Sumatera dan Selatan Jawa-Sumbawa. IPB.

Tangke, U., Karuwal, J. W. C., Mallawa, A., \& Zainuddin, M. 2017. Analisis Hubungan Suhu Permukaan Laut, Salinitas, Dan Arus Dengan Hasil Tangkapan Ikan Tuna Di Perairan Bagian Barat Pulau Halmahera. Jurnal IPTEKS Pemanfaatan Sumberdaya Perikanan, 3(5).

Tangke, U., Mallawa, A., \& Zainuddin, M. 2011. Analisis hubungan karakteristik oseanografi dan hasil tangkapan yellowfin tuna (Thunnus albacares) di perairan Laut Banda. Agrikan: Jurnal Agribisnis Perikanan, 4(2), 1-14. DOI: 29239/j.agrikan.4.2.1-4

Tangke U., 2014. Parameter populasi dan tingkat eksploitasi ikan tongkol (Euthynnus affinis) di perairan Pulau Morotai. Agrikan: Jurnal Ilmiah Agribisnis dan Perikanan. 7(1):74-81. DOI: 10.29239/j.agrikan.7.1.74-81.

Tangke U., Deni S., \& Aunaka A., 2018a. The Influence of Using Bait Types to the Number and Composition of Fishing Traps Catch in South Ternate Waters. IOP Conference Series: Earth and Environmental Science. 175(1):12231. DOI: 10.1088/1755-1315/175/1/012231.

Tangke U., Mallawa A., \& Zainuddin M., 2011. Analisis hubungan karakteristik oseanografi dan hasil tangkapan yellowfin tuna (Thunnus albacares) di perairan Laut Banda. Agrikan: Jurnal Agribisnis dan Perikanan. 4(2):1-14. DOI: 10.29239/j.agrikan.4.2.1-14.

Tangke U., Sangadji I., Rochmady R., \& Susiana S., 2018b. A population dynamic aspect of Selaroides leptolepis in the coastal waters of South Ternate Island, Indonesia. AACL Bioflux. 11(4):13341342.

Santos, A.M.P. 2000. Fisheries oceanography using satellite and airborne remote sensing methods: a review. Fisheries Research, 49:1-20.

Salamun., 2001. Komputer Teknik. Jurusan Planologi Fakultas Teknik. Universitas 45. Makassar.

Subani, W., 1982. Penangkapan Cakalang dengan Pole and Line. LPPL. No. 24. Jakarta.

Widodo, J., I Gede S.M., dan Subhat N. 1988. Sumberdaya Potensi dan Penyebaran Sumberdaya Ikan Laut di Perairan Indonesia. Komisi Nasional Pengkajian Stok Sumberdaya Ikan Laut - LIPI. Jakarta. 